\title{
The grammar of relative measurement *
}

\author{
Dorothy Ahn \\ Harvard University \\ Uli Sauerland \\ ZAS
}

\begin{abstract}
Relative measures such as percent and thirds relate one quantity to another. In several languages, determiner phrases containing relative measures can express two distinct construals: 1) The conservative construal in The company hired 55\% of the women considers the ratio of the company hires among all women. 2) The non-conservative construal in The company hired 55\% women is instead concerned with the ratio of women among the company hires. Other languages that distinguish the two construals using morphosyntactic means include German, Korean, Serbian, French, Georgian, Italian, and Hebrew. We present a syntactic and semantic analysis for the two construals. We argue that the non-conservative construal involves a different constituency of the measure-DP, and that focus semantics combined with a version of the copy theory of movement accounts for the non-conservative interpretation.
\end{abstract}

Keywords: quantification, measurement, relations, fractions, conservativity, universals, copy theory

\section{Introduction}

This paper is concerned with what we call relative measures, a class of measure nouns including fractions like thirds and proportion nouns like percent. Unlike absolute measures such as liter and gram, relative measures are concerned with how two amounts are related. Relative measures are built upon absolute measures: usually the underlying absolute measure is left unspecified, but we can distinguish between $20 \%$ by volume, by weight, or by units.

Our primary concern in this paper is how the syntax-semantics interface determines which two amounts are related by a relative measure. Relative measures in a number of languages seem to allow two different construals, as discussed in Ahn

* We would like to thank Gennaro Chierchia, Jenny Doetjes, Heejeong Ko, Chungmin Lee, Andreea Nicolae, Benjamin Spector, Kazuko Yatsushiro, and the audiences at NELS 45, DGfS 2015, GLOW 38, SALT 25, Olinco 2014, GGS 2014, and the Universities of Nantes, Tsukuba, and Potsdam for their helpful comments and suggestions. We would also like to thank everyone who has provided us with relevant linguistic data. This work was supported in part by BMBF Grant No. 01 UG1411 and DFG grant SA 925/11-1.

CO2015 Ahn \& Sauerland 
Ahn \& Sauerland

\begin{tabular}{ll} 
language(s) & morphological marking \\
\hline English & focus, case $($ of $)$, definiteness \\
German, Georgian, Greek & focus, case, definiteness \\
French, Italian & focus, definiteness \\
Korean & focus, case, definiteness, word order \\
Mandarin & focus \\
\hline
\end{tabular}

Table 1 Marking of non-conservative (vs conservative) construal of relative measures (from Ahn \& Sauerland 2015)

\& Sauerland 2015. Consider the two English sentences in (1) that illustrate the two construals. The morphosyntactic difference between the two examples in English is the presence of of the in (1a) and the presence of focus marking on the noun women in (1b).

(1) a. The company hired $55 \%$ of the women.

(conservative)

b. The company hired 55\% WOMEN. (non-conservative)

Semantically, the two construals target different quantity relations. (1a) looks at the ratio of the set $\mathrm{X}$ of women that the company hired to the total set of all women. (1b) also considers the ratio of the set $\mathrm{X}$ relative to some set, but it is relative to the set of all individuals that the company hired. So (1b) can be paraphrased as (2):

(2) $55 \%$ of those that the company hired are women.

We call the two construals illustrated in (1) conservative and non-conservative, respectively. Our terminology is motivated by the observation that (1a) is consistent with the Conservativity Universal formulated in Keenan \& Stavi 1986, while (1b) represents a counterexample to it (Ahn \& Sauerland 2015).

While we used English data to introduce the non-conservative construal, we feel that we understand the morpho-syntactic properties of the two construals better in other languages, specifically German and Korean. In Ahn \& Sauerland 2015 we show that the morphosyntactic distinction between the two construals is made by different means across languages as summarized in Table 1. One property that is present with the non-conservative interpretation across all languages we investigated is the focus on the noun associated with the measure.

In English, relative measures behave differently from adverbials as shown in (3), which suggests that $60 \%$ and the associated noun women form a constituent. 
The grammar of relative measurement

(3) The class has $\left\{\begin{array}{l}* 60 \% \\ \text { mostly }\end{array}\right.$ consisted $\left\{\begin{array}{l}* 60 \% \\ \text { mostly }\end{array}\right.$ of $\left\{\begin{array}{l}60 \% \\ \text { mostly }\end{array}\right.$ women.

Case and agreement patterns in languages like German provide further evidence for the constituency of the relative measure with the associated noun. The German data in (4) show that the two construals of relative measures are distinguished primarily by case marking (Sauerland 2014): when the noun students bears genitive case in (4a), the conservative construal arises. For the non-conservative construal in (4b), the measure noun percent and the noun students must agree in case - i.e., in the subject argument position, both receive nominative case. Thus, case agreement alone suggests constituency. Furthermore, the verb in both examples can agree with either of the two nouns (though agreement with the genitive in (4a) is marked), showing that neither noun in (4b) can unequivocally be an adverbial.
a. Ein Prozent Studierender arbeit-et/??-en hier.
One percent-NOM students-GEN work-SG/-PL
'One percent of students work here.'
(conservative)
b. Ein Prozent stuDIERende arbeit-et/-en hier.
one percent-NOM students $F_{F}$-NOM work here
'One percent of workers here are students.' (non-conservative)

The rest of the paper is organized as follows. In section 2, our proposal for conservative and non-conservative construals of relative measures is presented. We propose that relative measures are ambiguous between two distinct structures, where the non-conservative structure involves a covert movement of the measure NP. Section 3 presents data from Korean that supports our proposal: Korean only allows the non-conservative reading in a floating quantifier structure, and we argue that this is the overt form of the NP movement proposed in Section 2. Section 4 discusses attributive uses of the relative measure which also allows the non-conservative reading. Section 5 concludes with a brief note on how our work relates to broader discussions of weak definite quantifiers and conservativity.

\section{The analysis of relative measures}

\subsection{Conservative construals}

Previous work on measurement has mostly considered absolute measures. These are characterized by semantic intersectivity. 'Gram' is a typical example: '30 grams of gold' are both 30 grams heavy and entirely golden. Intersectivity is implicitly assumed as a universal property of the grammar of measurement by Krifka (1989), Schwarzschild (2006), Champollion (2010), Scontras (2014), and others. 
For example, Krifka (1989) proposes the analysis in (5a) and Schwarzschild (2006) the one in (5b). In both cases we have omitted the additional conjunct capturing the monotonicity requirement for simplicity.

(5) $\quad x$ is 5 ounces of (the) gold

a. $\quad$ ounces $(x)=5 \& \operatorname{gold}(x)$

b. $\exists \operatorname{Dim}: \operatorname{gold}(x) \&$ 5-ounces$(\operatorname{Dim}(x)) \quad$ (Dim: dimension)

Relative measures such as 5 percent of the gold and one twentieth of the gold appear in the same syntactic environment as absolute measures. But the intersective analysis in (5) seems implausible for relative measures. Consider example (6). Here, quarter can have an absolute measure interpretation referring to a quarter slice of a pizza. But (6) actually prefers a relative measure interpretation of quarters where it applies to the totality of two pizzas and therefore amounts to half of a single pizza, assuming both are the same size.

(6) Joe ate one quarter of the two pizzas.

As far as we know, only Ionin, Matushansky \& Ruys (2006) have proposed a semantics for relative measures. Namely, they propose that relative measures combine with the total substance by functional application as in the structure in (7).

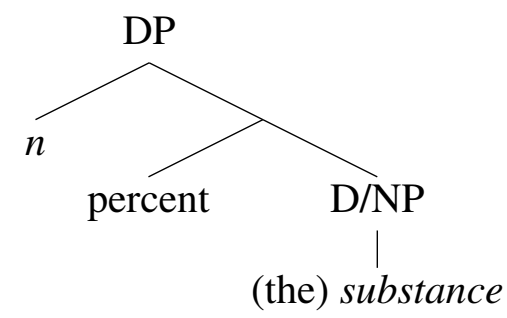

Our lexical entry for percent is shown in (8), where $\mu$ is a contextual variable for a measure function mapping entities of type $e$ to numbers. Typically with percent, $\mu$ is a measure of volume (e.g., in liters), a measure of weight (e.g., in grams), or a counting measure of atomic units. For fractions like thirds, the lexical entry would be essentially the same as (8) except for the denominator of the fraction to the right of the equals sign.

$$
\llbracket \text { percent } \rrbracket=\lambda x \in D_{e} \lambda n \in D_{d} \lambda y \in D_{e t} \cdot \frac{\mu(x \sqcap \oplus y)}{\mu(x)}=\frac{n}{100}
$$

The lexical entry (8) entails that the substance argument of a relative measure must be of type $e$. This predicts that expressions of other types should be blocked from this position as in the account of the partitive constraint by Ladusaw (1982). The 
The grammar of relative measurement

prediction is confirmed by data like (9), where omission of the definite determiner results in ungrammaticality as also noted in Ionin et al. 2006. ${ }^{1}$

(9) John ate sixty percent of *(the) apples.

But there are also examples like those in (10) that appear to be problematic. ${ }^{2}$

a. Ten percent of Americans smoke Marlboro.

b. Ninety percent of water is undrinkable.

In both examples in (10), the measurement is relative to a maximal entity; that of all Americans and all water, respectively. We assume that, if the substance DP is not overtly definite (i.e., type $e$ ), maximization must apply in the form of the supremum function. For concreteness, assume that bare nouns denote predicates. Then the relevant concept of supremum is stated in two different ways in (11). ${ }^{3}$

$$
\sup (c)=\bigoplus_{c(x)=1} x=\imath x . \forall y(c(y) \rightarrow y \sqsubseteq x)
$$

The supremum operator, however, cannot apply freely. We assume that languages that have an overt definite determiner (interpreted as a maximum operator) prefer using it instead of the supremum operator when possible. This predicts the difference in (9). We assume (10) to exemplify cases where the maximum is undefined, but the supremum is.

In sum, our analysis of the conservative construal of relative measures does not depart much from the analysis of absolute measures. We have argued that it involves a function-argument relation between the measure and the substance, rather than an intersective semantics.

\subsection{Non-conservative construals}

Does the non-conservative construal of measures have the same structure as the conservative construal? Most current analyses assume only one syntactic structure

1 A substantial amount of the literature on measures draws a distinction between partitive and pseudopartitive constructions, which is based on the presence/absence of a definite determiner. This terminology has taken attention away from the goal of finding lexical and structual semantics independent of particular constructions.

2 Examples like (i) aren't problematic since quantifier raising predicts the acceptability of (i).

(i) Two thirds of every package is styrofoam.

3 We adopt the standard assumption that the part-whole relation $\sqsubseteq$ among individuals constitutes a semi-lattice (Link 1983 and others). 
of measure structures. Specifically, consider work on languages like German where case marking is used to distinguish the two construals. Descriptive grammars of German such as Dudenredaktion 2009 and Zifonun, Hoffmann \& Strecker 1997 note that absolute measures also allow two case-marking patterns as shown in (12) (cf. (4)). But they assume structural uniformity despite the variation in case marking. This uniformity seems initially corroborated by the fact that there is no detectable difference in meaning in (12).

a. Ein Dutzend Studierender arbeit-et/?*-en.

One dozen-NOM students-GEN work-SG/-PL

'One dozen of students work.'

(conservative)

b. Ein Dutzend stuDIERende arbeit-et/-en hier.

One dozen-NOM students ${ }_{F}$-NOM work here

'One dozen of workers here are students.' (non-conservative)

The semantic difference with relative measures in (4) is a new observation. ${ }^{4} \mathrm{We}$ believe that it motivates a structural difference for all measures, i.e., even for (12). It is predicted that no semantic difference can be observed in (12) because absolute measures have an intersective semantics. As the graphics in (13) illustrate, the two construals of a relative measure in (4) consider the relation between the intersection of the restrictor $(\mathrm{R})$ and the scope $(\mathrm{S})$ sets to either one of the two. But for an absolute measure, only the intersection itself enters the truth-conditions.

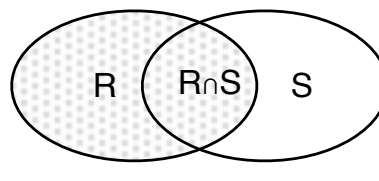

conservative

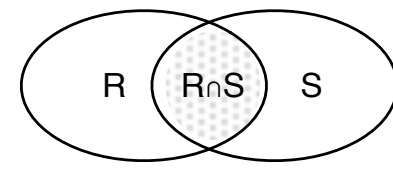

intersective

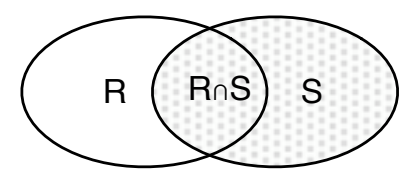

non-conservative

Our syntactic proposal aims to capture the fact that the measure noun and the substance noun exhibit symmetric behavior with respect to case and agreement in (4) on the non-conservative construal, whereas there is an asymmetry between the measure noun and the substance noun with the conservative construal. Thus, for the conservative structure, we keep a structure where the measure noun is the head of the measure structure and takes the substance noun as its argument. For the non-conservative construal, we adopt in part a proposal by Ott (2012) for other cases in German where two nouns must agree in case with each other. The basic idea of Ott's proposal is that two complex nominal phrases can be joined together

4 Herburger (1997) and Westerståhl (1985) discuss non-conservative readings of weak determiner quantifiers like few and many. We discuss how relative measures differ from weak determiners and compare our analysis to that of Herburger (1997) in the conclusion. 
The grammar of relative measurement

exceptionally and share their case properties, but they can only form an unstable constituent. Specifically, Ott proposes an analysis of split topicalization sentences such as (14) (van Riemsdijk 1989), where two nominal phrases are related to the object position of the verb found and bear accusative case: $a$ solution and a better (one).

$$
\begin{aligned}
& \text { Eine Lösung hat sie eine Bessere als ich gefunden. } \\
& \text { a solution.ACC has she a better.ACC than me found } \\
& \text { 'She has found a better solution than I.' }
\end{aligned}
$$

Ott (2012) argues that the two nominal phrases form what he calls an unstable constituent at some point of the syntactic derivation of (14). Applying ideas of Chomsky (2013), Ott analyzes an unstable constituent as a phrase where it cannot be decided which constituent is the head. Ott proposes that a constituent unstable in this sense must be split by overt movement, and that therefore the two nominal phrases in (14) must be split. Ott also extends his proposal for floating quantifiers that agree with the NPs they associate with.

The non-conservative construal shares case-agreement with Ott's cases, but it differs with respect to the instability. While the phrases in Ott's cases are not allowed to form a surface constituent, the measure and the associated noun must form a constituent in (4b) - both word-order variants in (15) are ungrammatical. ${ }^{5} \mathrm{We}$ adopt Ott's syntactic proposal, but propose that the instability of non-conservative measures requires an LF rather than a PF-split.

$$
\begin{aligned}
& \text { a. Ein Prozent arbeit-et/-en hier StuDIERende. } \\
& \text { One Percent-NOM work here students } F_{-N O M} \\
& \text { b. ?* StuDIERende arbeit-et/-en hier ein Prozent. } \\
& \text { students } F \text {-NOM work here one percent-NOM }
\end{aligned}
$$

In this spirit, we propose that percent in English also is ambiguous between two distinct structures. Specifically, we propose that, in the non-conservative structure, a contextual, focus-sensitive restrictor $C$ fills the argument position of percent as indicated in (16a), where the structure of the conservative construal is also sketched on the right for comparison. In the non-conservative construal, the substance NP is merged to the percent NP forming an unstable constituent in the sense of Ott 2012, where '- ' indicates the lack of a phrase label. ${ }^{6}$

5 In both cases, there is a clear contrast with an adverbial structure with the zu einem Prozent ('at one percent') instead of ein Prozent. In the adverbial structure, the verb must agree with the plural of Studierende; in contrast to (4b), singular verb agreement is not possible.

6 We discuss examples like the ten percent women that work here further below. We mention them here because they show that the ten percent women has the distribution of an NP. 
a. Non-Conservative

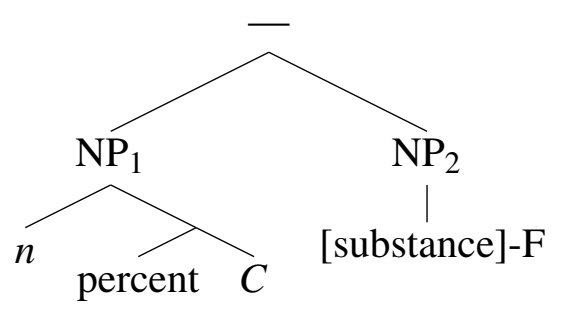

b. Conservative

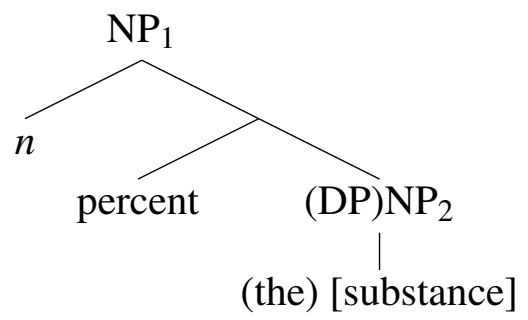

The structure in (16a) can predict the morphosyntactic properties of non-conservative construals in English and German. Genitive case in (16a) is not available because $C$ occupies the position where genitive case is assigned. Specifically in English, where of is a reflex of the genitive case, of is omitted because $C$ is silent. ${ }^{7}$ In German, and also in Georgian and Greek, we assume that case is assigned to the constituent of the two NPs in (16a) and therefore the measure noun and the substance noun agree in case. Furthermore, the verb can agree with either of the two nouns in (16a) because the two NPs have the same syntactic status.

We now focus on the semantic derivation of the non-conservative construal. The concrete example we use for demonstration is (17). While the example is in German, we use the English gloss '55\% women are presenting' in what follows.

55 Prozent FRAUen tragen (dieses Jahr) bei GLOW vor.

55 percent women $_{F}$ present (this year) at GLOW PART

' $55 \%$ of the presenters at GLOW this year are women.'

The subject of (17) has the non-conservative structure in (16a). We assume that $C$ denotes a set of properties, i.e., is of type $\langle e t, t\rangle$. The supremum operator defined in (11) cannot apply to $C$, and therefore we assume a second, higher order supremum operator in (18).

$$
\sup ^{\prime}(C)=\bigoplus_{c \in C} \bigoplus_{c(x)=1} x
$$

We assume that $\mathrm{NP}_{1}$ in (16a) must move at LF to a scope position. This movement may be motivated by the syntactic instability discussed in Ott. The movement furthermore resolves a type conflict since the entire constituent in (16a) is predicted to have type $t$ and therefore couldn't be the subject of are presenting. We propose that the movement results in the structure in (19).

7 In contrast to English, the French non-conservative construal contains a partitive preposition de (Ahn $\&$ Sauerland 2015), so we assume that $d e$ is a preposition taking the silent $C$ as an argument. 
The grammar of relative measurement

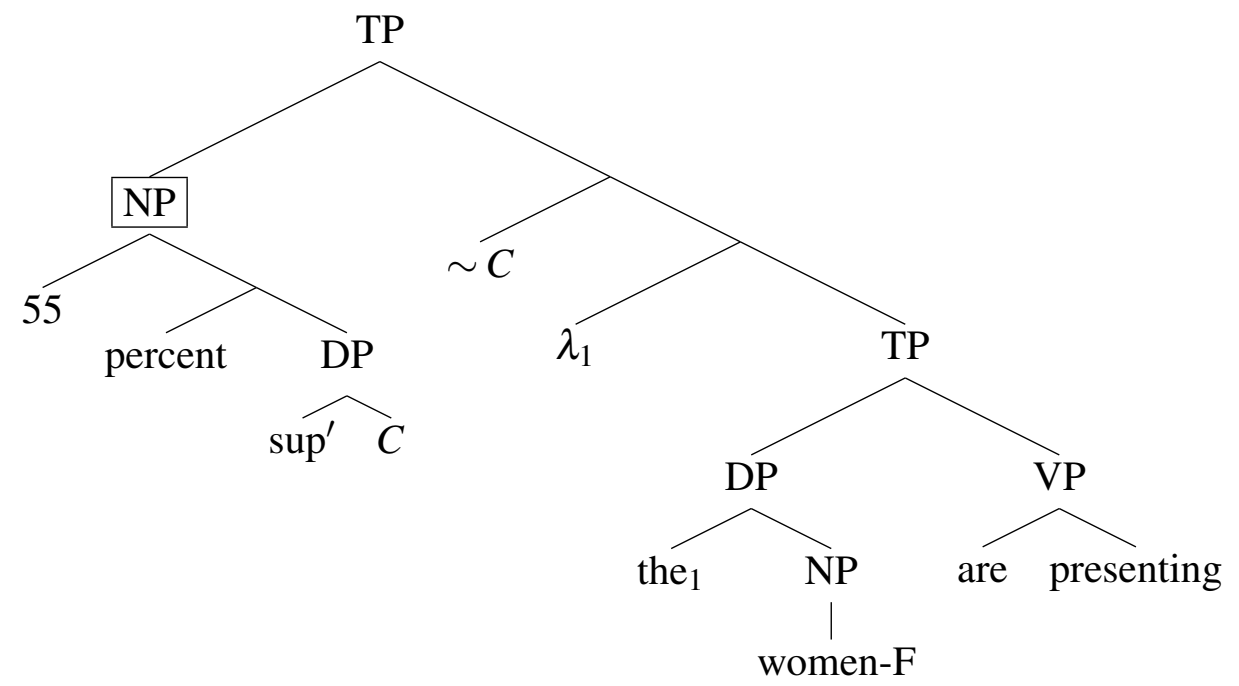

As (19) shows, we assume that the movement must leave behind not just an index, but a definite description as the trace as in the copy theory of movement (Fox 1999; Sauerland 1998, 2004; and others). For this paper, we adopt the indexed definite determiner in (20).

$$
\llbracket \text { the }_{n} \rrbracket^{g}=\lambda P . P(g(n)): g(n)
$$

The insertion of the definite, however, differs from other cases of movement. Namely, we assume that in (19) the entire moved phrase is replaced by the indexed definite determiner. This is necessary because otherwise movement would not resolve the type mismatch arising at the level of combination of the verb and its argument.

Movement also provides a site for the focus licensor $\sim$, determining $C$ (Rooth 1992). Assuming that the only alternative to women is men, $C$ has only the two elements in (21).

$$
\mathrm{C}=\{\lambda \mathrm{x} . \mathrm{x} \text { is a female presenter, } \lambda \mathrm{x} . \mathrm{x} \text { is a male presenter }\}
$$

The resulting interpretation is shown in (22): $55 \%$ of all presenters are women presenters.

$$
\text { [55 percent } \left.\sup ^{\prime} C\right] \sim C\left[\lambda_{1} \text { the }_{1}\left(\text { women }_{F}\right) \text { are presenting }\right]
$$

This completes our account of the non-conservative construals of relative measures. As we already discussed briefly, structure (22) might also be possible with absolute measures, but the interpretation predicted would not differ from the one arising from the conservative structure. 
Ahn \& Sauerland

\subsection{Account for narrow focus}

Our proposal can be extended to account for narrow focus readings which arise when the NP construed with the measure noun is complex:

(23) 60 Prozent [Frauen aus DEUTschland] sitzen im Publikum.

60 percent women from Germany ${ }_{F}$ sit in the audience

' 60 percent of the women in the audience are German.'

In (24), the focus alternative set is (25), and maximization results in the plurality of all women who are in the audience. This correctly predicts the reading that $60 \%$ of all women sitting in the audience are from Germany.

$$
\begin{aligned}
& {\left[60 \% \sup ^{\prime} C\right] \sim C\left[\lambda_{1} \text { the }_{1} \text { (women from Germany }{ }_{F}\right. \text { ) sit in the audience] }} \\
& C=\{\lambda x . x \text { is a female audience member from France, } \\
& \lambda x . x \text { is a female audience member from Italy, } \\
& \lambda x . x \text { is a female audience member from Germany,... }
\end{aligned}
$$

\section{Non-conservative readings in Korean}

We now present another argument for our proposal from Korean. Specifically, we show that in Korean, the movement of the measure NP proposed above is realized overtly, forming a quantifier float structure (Ahn 2012). This difference from German and English is not surprising as Korean tends to identify intended scope orderings overtly (Beck \& Kim 1997).

We see this overt movement in the following way. (26a) and (26b) respectively show the conservative and the non-conservative construals. While in (26a) the substance noun woman and the measure noun fifty-percent appear inside the accusative-marked DP, in (26b) fifty-percent appears outside the case-marked DP.

$$
\begin{aligned}
& \text { a. Hyosa-ka [yeca-(uy) osip-phulo]-lul ceyyonghayssta. } \\
& \text { company-NOM woman-GEN fifty-percent-ACC hired } \\
& \text { 'The company hired fifty percent of the women.' (conservative) } \\
& \text { b. Hyosa-ka YECA-lul osip-phulo ceyyonghayssta. } \\
& \text { company-NOM woman }{ }_{F} \text {-ACC fifty-percent hired } \\
& \text { 'The company hired fifty percent women.' }
\end{aligned}
$$

The sentences (26a) and (26b) are parallel to the the postnominal structure shown in (27a) and the floating quantifier (FQ) structure shown in (27b), which are found with intersective, cardinal quantifiers in Korean (Kim 1976; Shin 2009; and others). ${ }^{8}$

8 Korean also allows pre-nominal numeral quantification as in (i): 
The grammar of relative measurement

a. John-i [sakwa twu-key]-lul mekessta.

John-NOM apple two-CL-ACC ate

'John ate two apples.'

(post-nominal)

b. John-i sakwa-lul twu-key mekessta.

John-NOP apple-ACC two-CL ate

'John ate two apples.'

\subsection{Syntactic account for Korean}

Our proposal can be directly applied to the FQ structure in Korean, with the only difference being that the movement of the measure NP occurs overtly. We illustrate this with (28a) and (28b), which have the relative measure quantifying the subject.
a. [Kyosu-(uy) isip-phulo]-ka wassta.
professor-GEN twenty-percent-NOM came
'20 percent of the professors came.'
(conservative)
b. KYOSU-ka isip-phulo wassta.
professor $_{F}$-NOM twenty-percent came
'20 percent of those who came were professors.' (non-conservative)

In order to get from the conservative structure in (28a) to the non-conservative structure in (28b), twenty-percent floats out of the constituent. The remnant containing the substance noun professor moves for case, but reconstructs.

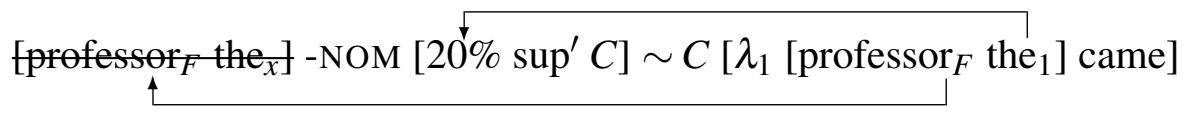

The availability of the non-conservative reading in the FQ structure has been first observed in Park 2007 with the Korean quantifier taypwupwun ('most'). Park analyzes taypwupwun as an adverbial quantifier that quantifies over events. Relative measures, however, differ from adverbial quantifiers like taypwupwun in that they form a constituent with the associated noun. This is shown by the contrast in (30) where $20 \%$ is much more restricted than taypwupwun in distribution.

$$
\begin{aligned}
& \text { a. (Taypwupwun) KYOSWU-ka (taypwupwun) wassta. } \\
& \text { most } \text { professor }_{F} \text {-NOM most came }
\end{aligned}
$$

'Professors mostly came.'

\footnotetext{
(i) John-i [twu-key-uy sakwa]-lul mekessta.

John-NOM two-CL-GEN apple-ACC ate

'John ate two apples.'
}

However, we follow Watanabe (2008) in assuming the pre-nominal structure to derive from the post-nominal structure and only discuss the post-nominal and the FQ structures. 


\section{b. (*Isip-phulo) KYOSWU-ka (isip-phulo) wassta. twenty-percent professor-NOM twenty-percent came '20 percent of those who came were professors.'}

\subsection{Further prediction: case-marked FQ in Korean}

The FQ structure in (28b) has another variant, in which both the substance noun and the floated quantifier receive case marking, as shown in (31). The case-marked structure, however, does not allow non-conservative interpretations, even if the substance noun professor is focused.

$$
\begin{aligned}
& \text { KYOSU-ka isip-phulo-ka wassta. } \\
& \text { professor }_{F} \text {-NOM twenty-percent-NOM came } \\
& \text { '20 percent of the professors came.' }
\end{aligned}
$$

(conservative)

Ko (2005) for independent reasons analyzes the case-marked FQ as involving an adverbial structure taking a null argument pro. ${ }^{9}$ Because pro, and not $C$, serves as the argument of percent, our proposal predicts only the conservative interpretation to be possible, and this prediction is borne out. This also strengthens the cross-linguistic generalization that non-conservative interpretations are not possible with definite nouns (Ahn \& Sauerland 2015).

\section{Non-conservative interpretation with attributive relative measure}

The non-conservative interpretation also arises when the relative measure is used attributively, as in (32). Despite our previous generalization that English does not allow non-conservative readings in the subject position, (32b) has the relative measure quantifying the subject.

a. The $30 \%$ women MIT hired last year are listed in the directory.

b. The $20 \%$ women who attended the party enjoyed it.

German and Korean also allow non-conservative readings with attributive relative measures, as shown in (33) and (34).

9 Ko (2005) looks at cardinal quantifiers that receive case-marking. 'Case-marked NQs', as Ko (2005) calls them, are analyzed as secondary predicates that take pro as their arguments. This pro refers to the substance noun if it is present in the sentence. Ko notes that the 'pro Case-marked NQ' constituent is similar to 'of them' in the English paraphrase in (i).

(i) Students, three of them, came. 
The grammar of relative measurement

Die 20 Prozent Studierende, die hier arbeiten, sind zufrieden.

the 20 percent students.NOM who here work are satisfied ??' $20 \%$ of students work here and these students are satisfied.'

' $20 \%$ of workers here are students and these workers are satisfied.'

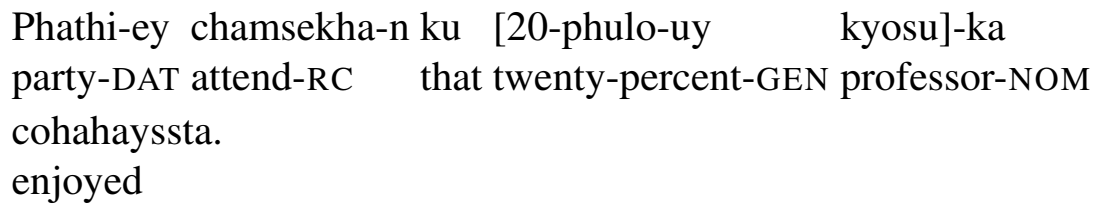

We cannot analyze these sentences as the measure NP moving to take scope over the matrix IP; this leads to the wrong interpretation where the scope argument of $20 \%$ is the whole DP containing the relative clause. The desired interpretation is where the content of the relative clause forms the restrictor argument. For example, in (32b), the interpretation we want is that $20 \%$ of those who came to the party were professors, and those professors enjoyed the party. In other words, the material outside the relative clause does not enter into the interpretation of the relative measure.

We are not the first to observe such scope restrictions in attributive uses of quantifiers. This pattern is exactly parallel to what Solt (2014) observes with Qadjectives few and many when they are used attributively as in (35).

The many/few women who attended enjoyed the party.

Solt (2014) proposes an analysis involving relative clause constructions. Specifically, the quantifier is argued to reconstruct into the relative clause, being interpreted independently of the rest of the sentence as a presupposition. A proform $R$ is posited, and this has the right value to pick up the properties from the relative clause. For example, in (35), the $R$ is the property of being a plurality of women who attended, and the DP denotes the maximal plurality of such women with the presupposition contributed by the relative clause that they were many or few in number.

A parallel account can be adopted for our example in (32b): $20 \%$ women is reconstructed, and the computation of the non-conservative interpretation happens inside the relative clause. The proform $R$ picks up the property of being a plurality of women who attended, and the relative clause contributes the presupposition that they were $20 \%$ of those who attended. ${ }^{10}$

10 While we assume that this applies to Korean in a parallel way, there are two questions that remain. First, while in the matrix clause the movement of the measure NP had to be overt, this is not the case in the embedded clause. Second, the genitive case-marker $u y$ appears in the attributive use. We could assume that $u y$ is simply inserted in the phonetic derivation as in the discussion of the Japanese no in Watanabe (2008), but this must be investigated further. 
The $20 \%$ women (that there were) who attended

a. the $\left[N P{ }_{-}\left[C P\right.\right.$ that $\left[\left[20 \% \sup ^{\prime} C\right] \sim C\left[\lambda_{1}\right.\right.$ the $_{1}\left(\right.$ women $\left._{F}\right)$ attended $\left.\left.\left.]\right]\right]\right]$

This analysis where the measure noun is reconstructed to the relative clause and interpreted inside can also account for the conservative reading that is available for these sentences in German and Korean. In English examples such as those in (32), only the non-conservative reading is available: We are referring to the plurality of women who were $30 \%$ of those hired by MIT in (32a), and to the plurality of women who were $20 \%$ of the party attendees in (32b). In German and Korean, however, the conservative reading is also possible. For example, in (33), we can refer to either the plurality of students who are $20 \%$ of all workers (non-conservative; the dominant reading), or the plurality of students who are $20 \%$ of all students (conservative). The same holds for Korean in (34). All we need to say to account for this reading is that what reconstructs into the relative clause is the conservative structure in (16b), which does not require the measure NP movement and thus gives the conservative reading. What restricts this reading in the English example, however, is not clear.

\section{Conclusions}

In this paper we have shown that relative measure nouns such as fractions and percent are ambiguous between conservative and non-conservative readings. Focusing on German and Korean, we have presented a syntactic and semantic account of both construals. Specifically, we argue that measures in general are structurally ambiguous between two structures. In non-conservative construals, the measure noun takes as its argument a focus-sensitive restrictor, forming an unstable constituent with the associated noun. The measure NP moves, resulting in a reading where the restrictor of the measure noun is formed by what remains after movement. While this movement of the measure NP is covert in English and German, it is realized overtly in Korean in a floating quantifier structure. Lastly we discuss non-conservative readings that arise in attributive uses of relative measures, showing that we can account for them by adopting the proposal in Solt (2014), which proposes that the interpretation of attributive Q-adjectives involves a relative clause structure.

To conclude we briefly address the relation of our work to two important discussions in the semantics of quantification: the interpretations available with weak determiner quantifiers and the derivation of conservativity.

\subsection{Relative measures vs. weak vague quantifiers}

The non-conservative readings we note are reminiscent of a discussion of readings available for weak vague determiners such as many and few. Westerståhl (1985) first 
The grammar of relative measurement

notes that these sometimes allow a reading that can be paraphrased by reversing the role of the VP and the NP; specifically, a paraphrase of (37a) would be Few of the applicants were cooks. Herburger (1997) introduces the term focus-affected (f-a) readings for such interpretations.

a. Few COOKS applied.

(Herburger 1997)

b. $* 10$ percent COOKS applied.

What is relationship between the focus-affected readings and the non-conservative readings of relative measures? At this point, we see them as independent phenomena, and assume the account of Cohen (2001) for them, as we discuss in Ahn \& Sauerland 2015. One reason for this is that subjects in English allow focus-affected readings, but not non-conservative readings of relative measures as shown in (37b). Secondly, the weak, vague determiners differ from non-conservative relative measures in German as well: few and many bear adjectival morphology and must agree with the head noun regardless of the reading as in (38).

$$
\begin{aligned}
& \text { Wenige Köche haben sich beworben. } \\
& \text { few.NOM.PL cook.NOM.PL have REFL applied }
\end{aligned}
$$

'Few of the applicant were cooks.' / 'Few of the cooks applied.'

Thirdly, the readings seem to also differ with respect to individual level predicates. Herburger (1997) points out that vague quantifiers do not give rise to f-a readings in the subject position of individual level predicates. ${ }^{11}$ But, as the contrast in (39) shows the non-conservative readings of relative measures are not restricted in the same way. (We use a Korean example because English does not allow the non-conservative structure lacking of in the subject position.)

a. *Few/many COOKS know how to make a soufflé.

b. YOLISA-ka 90-phulo swuphulley-lul mantul-cwul-anta. cook $_{F}$-NOM 90-percent soufflé-ACC know.how.to.make ' $90 \%$ of those who know how to make soufflé are cooks.'

Despite these empirical differences, our account of non-conservative construals of relative measures is similar to that of Herburger (1997) and specifically a version of it Krasikova (2011) develops. While at this point we think that the weak vague determiners require an account on their own such as that of Cohen (2001), we

11 Cohen (2001) points out (i) as a potential counterexample. But we think (i) might also have readings where the predicate isn't an individual level predicate.

(i) Many SCANDINAVIANS have a Nobel Prize in literature. 
note this similarity between the two phenomena and believe that at some point a unification of the accounts can be accomplished.

\subsection{Conservativity}

There are broadly two theoretical directions to understand conservativity. The first set includes cognitive accounts (Keenan \& Stavi 1986; and others) which treat conservativity as a processing ban on the interpretation of natural language determiners. The second approach makes use of the copy-theoretic accounts (Chierchia 1995; Romoli 2015; and others), which argue that deteminers are free to denote conservative or non-conservative functions, but that non-conservative construals simply do not arise because they are contradictory, tautological, or indistinguishable from meanings given by the corresponding conservative counterpart.

If cognitive accounts refer to processing of the surface form, our data falsify them. On the other hand, there is a way of deriving non-conservative construals of relative measures under the copy-theoretic account of the conservativity. Consider the analysis of $55 \%+$ partitive under this account:
a. $55 \%$ of the women are presenting.
b. [55\% of the women] [ $\lambda_{1}$ the ${ }_{1}$ woman is presenting]

The crucial difference in the non-conservative structure is that what moves is the measure NP containing $C$, not women.

a. $55 \%$ women are presenting.

b. $55 \% \mathrm{C}\left[\lambda_{1}\right.$ the ${ }_{1}$ woman is presenting $]$

With this configuration, the resulting meaning is in fact distinguishable from the meaning that would arise from the corresponding conservative construal. Thus, our analysis of non-conservative, focus-sensitive readings of relative measures provides further evidence for the copy-theoretic accounts of conservativity.

\section{References}

Ahn, Dorothy. 2012. Reverse quantification in Korean. Unpublished manuscript, Harvard University.

Ahn, Dorothy \& Uli Sauerland. 2015. Non-conservative quantification with proportional quantifiers: Crosslinguistic data. In Thuy Bui \& Deniz Özy1ldız (eds.), The Forty-Fifth Annual Meeting of the North East Linguistic Society (NELS 45), vol. 1, 1-10. GLSA, University of Massachusetts. 
The grammar of relative measurement

Beck, Sigrid \& Shin-sook Kim. 1997. On wh- and operator scope in Korean. Journal of East Asian Linguistics 6. 339-384.

Champollion, Lucas. 2010. Parts of a whole: Distributivity as a bridge between aspect and measurement: University of Pennsylvania PhD dissertation.

Chierchia, Gennaro. 1995. Dynamics of Meaning. University of Chicago Press.

Chomsky, Noam. 2013. Problems of projection. Lingua 130. 33-49.

Cohen, Ariel. 2001. Relative readings of 'many', 'often', and generics. Natural Language Semantics 9. 41-67.

Dudenredaktion (ed.). 2009. Duden. Die Grammatik. Der Duden in zwölf Bänden, Band 4. Mannheim, Germany: Bibliographisches Institut 8th edn.

Fox, Danny. 1999. Reconstruction, variable binding and the interpretation of chains. Linguistic Inquiry 30. 157-196.

Herburger, Elena. 1997. Focus and weak noun phrases. Natural Language Semantics 5(1). 53-78.

Ionin, Tania, Ora Matushansky \& Eddy G. Ruys. 2006. Parts of speech: Toward a unified semantics for partitives. North East Linguistic Society (NELS) 36. 357-370.

Keenan, Edward L. \& Jonathan Stavi. 1986. A semantic characterization of natural language determiners. Linguistics and Philosophy 9. 253-326.

Kim, Y.-H. 1976. Hankuk-eo sulyanghwa kumun-uy bunseok ('Analysis of Korean quantifier structures'). Eoneohak ('Linguistics') 1(2). 89-112.

Ko, Heejeong. 2005. Syntactic edges and linearization: Massachusetts Institute of Technology PhD dissertation.

Krasikova, Sveta. 2011. On proportional and cardinal 'many'. In Generative Grammarin Geneva (GG@G), vol.7, 93-114. Geneva, Switzerland.

Krifka, Manfred. 1989. Nominalreferenz und Zeitkonstitution. W. Fink.

Ladusaw, Bill. 1982. Semantic constraints on the English partitive construction. In Daniel P. Flickinger, Marlys Macken \& Nancy Wiegand (eds.), West Coast Conference on Formal Linguistics WCCFL, vol. 1, 231-242. Stanford, Calif.: CSLI, Stanford University.

Link, Godehard. 1983. The logical analysis of plurals and mass terms: A lattice theoretical approach. In R. Bäuerle, C. Schwarze \& A. von Stechow (eds.), Meaning, Use, and the Interpretation of Language, 302-323. Berlin: de Gruyter.

Ott, Dennis. 2012. Local Instability: Split Topicalization and Quantifier Float in German. Linguistische Arbeiten. De Gruyter.

Park, Yugyeong. 2007. A study on the semantic characteristics of the proportional quantifier floating in Korean. Seoul, Korea Seoul National University MA thesis. van Riemsdijk, Henk. 1989. Movement and regeneration. In Paola Beninca (ed.), Dialect Variation and the Theory of Grammar, 105-135. Foris Publications.

Romoli, Jacopo. 2015. A structural account of conservativity. Semantics-Syntax 
Interface 2(1). 28-57.

Rooth, Mats. 1992. A theory of focus interpretation. Natural Language Semantics 1. 75-116.

Sauerland, Uli. 1998. The meaning of chains. Cambridge, Mass.: Massachusetts Institute of Technology $\mathrm{PhD}$ dissertation.

Sauerland, Uli. 2004. The interpretation of traces. Natural Language Semantics 12. 63-127.

Sauerland, Uli. 2014. Surface non-conservativity in German. In Empirical Issues in Syntax and Semantics 10, 125-142.

Schwarzschild, Roger. 2006. The role of dimensions in the syntax of noun phrases. Syntax 9(1). 67-110.

Scontras, Gregory. 2014. The semantics of measurement. Cambridge, Mass.: Harvard University PhD dissertation.

Shin, Keun Young. 2009. Numeral quantifiers: NP modifiers and relational quantity nominals. Language Research 45. 131-156.

Solt, Stephanie. 2014. Q-adjectives and the semantics of quantity. Journal of Semantics 32(2). 221-273.

Watanabe, Akira. 2008. The structure of DP. In Shigeru Miyagawa \& Mamoru Saito (eds.), The Oxford Handbook of Japanese Linguistics, 513-540. Oxford, UK: Oxford University Press.

Westerståhl, Dag. 1985. Logical constants in quantifier languages. Linguistics and Philosophy 8(4). 387-413.

Zifonun, Gisela, Ludger Hoffmann \& Bruno Strecker. 1997. Grammatik der deutschen Sprache (3 volumes). Berlin: de Gruyter.

Dorothy Ahn

Dept of Linguistics

Boylston, Third Floor

Cambridge, MA 02138

USA

dorothyahn@g.harvard.edu
Uli Sauerland

ZAS

Schützenstr. 18

10117 Berlin

Germany

uli@alum.mit.edu 